\title{
Ilicitud de las encuestas electorales
}

\section{Jorge Fernández Ruiz}

\section{Sumario:}

I. Introducción

II. De los modos de asumir el ejercicio del poder público

III. El sigilo del voto

IV. Justificación del secreto del voto

V. La encuesta electoral

VI. Recapitulación

VII. Conclusiones

VIII. Bibliografía 


\section{Introducción}

La lucha por el poder es una constante en la historia de la humanidad; mas no se trata simplemente de una lucha física y material por el poder, sino más bien de la lucha por los principios, por los fines y por el control del poder. Los peores males de la humanidad derivan con lamentable frecuencia del desvío de poder, es decir, de la desnaturalización de la potestad pública en beneficio de unos cuantos detentadores de ella y en perjuicio de la dignidad humana, en confirmación de la tesis hobbesiana de que el hombre es el lobo del hombre. De ahí la aspiración milenaria resumida en la frase de Montesquieu: "Que por la misma disposición de las cosas, el poder detenga al poder."

Los esfuerzos realizados para esa contención del poder, por el propio poder, se registran en el marco de la democracia, en cuyos orígenes sólo conoció la forma directa, su expresión era el autogobierno, la asamblea popular tenía a su cargo la toma de decisiones respecto de los asuntos concernientes a la cosa pública; en el ágora, la antigua Hélade; en los comicios, la antigua Roma, resolvían popularmente los asuntos tocantes a la comunidad; eran los ciudadanos congregados en asamblea pública, quienes adoptaban las resoluciones de la colectividad en la democracia directa; dicho de otra manera: la ciudadanía, sin intermediación alguna ejercía por sí y ante sí las atribuciones de su soberanía.

La democracia ateniense, paradójicamente aristocrática — se desarrolló en un régimen económico esclavista-, pronto se manifestó incapaz para el autogobierno; el crecimiento constante del número de asuntos a cargo de la asamblea popular obligó a ésta a aumentar la frecuencia y duración de sus reuniones; el incremento en las cargas del autogobierno condujo a la delegación del ejercicio de sus funciones, mediante la institución de la representatividad, primero en su forma más pura: por sorteo $\mathrm{y}$, ante sus inconvenientes, posteriormente se dejó a la voluntad de la mayoría ciudadana la facultad de elegir a quienes le habían de representar en el ejercicio de las funciones públicas inherentes a la actividad gubernamental.

1 Montesquieu, El espíritu de las Leyes, trad. de Mercedes Blázquez y Pedro de Vega, Barcelona, Tecnos, 1984, t. I, p. 142. 


\section{De los modos de asumir el ejercicio del poder público}

El arribo al ejercicio del poder público admite diversas formas empleadas a través del tiempo y del espacio.

La vida en sociedad derivada del sentido gregario de la humanidad implica una organización que en sus diversos niveles y etapas reclama una dirección, una conducción, un mando, un poder, que para ejercitarse requiere de depositarios, vamos, de gobernantes cuya designación primitivamente es casi inconsciente y espontánea, mediante un inconsulto consenso entre el que manda y los que obedecen. En la horda y el clan, cuando el poder no se ha institucionalizado, cuando aún no se ha producido la escisión entre los que mandan y los que obedecen, surge de manera espontánea el depositario del poder para acometer una determinada empresa en común; cumplida aquella empresa concluye el depósito del poder y no volverá a depositarse sino hasta cuando se acometa otra empresa comunitaria, entonces surgirá de nuevo espontáneamente el depositario del poder, quien podrá ser el mismo de la empresa anterior u otro distinto; porque en sus inicios el depositario del poder ni se elige ni se escoge, sino que, como dijera Maurice Duverger: "Aparece como un fenómeno tan natural como el agua, el fuego, el granizo y la lluvia en el universo físico". ${ }^{2}$

Posteriormente se registran otras formas de acceder al ejercicio del poder público, como la violencia, que confiere el poder al amparo del derecho del más fuerte; entre las primeras manifestaciones del poder político encontramos que los más fuertes se erigen en sus depositarios, pues sin otra razón que su propia fuerza, se autodesignan gobernantes, aun contra la voluntad de la mayoría del pueblo gobernado, por lo que detentan un poder ilegítimo. En esta manera de convertirse en gobernante se inscribe lo mismo la conquista que la revolución, la usurpación y el golpe de Estado.

La historia relata repetidos casos de quienes una vez obtenido el depósito del poder público de cualquier modo, luego lo han incluido en su personal patrimonio a efecto de volverlo hereditario, por lo que la herencia se instituye como una forma más de designar a los gobernantes, la cual después de siglos de emplearse ha declinado conside-

2 Duverger, Maurice, Instituciones políticas y derecho constitucional, trad. de Isidro Molas y otros, 5a. ed., Barcelona, Ariel, 1970, p. 28. 
rablemente como resultado de los perseverantes embates de quienes pregonan la igualdad como cualidad connatural a la dignidad de los seres humanos, censuras que se resumen en la célebre frase atribuida a Lord William Rutherford: "Ningún hombre sale del vientre de su madre con una diadema en la cabeza o un cetro en la mano".

Otra forma de convertirse en gobernante es la cooptación, que se puede explicar como el método por el cual el gobernante en turno designa a su sucesor. En otro sentido Giacomo Sani indica que "El término cooptación denota un sistema de integración de un cuerpo colegiado - directivo o consultivo - por el cual uno o más miembros son elegidos bajo designación de los miembros ya en funciones. ${ }^{3}$

El sistema estadounidense establece una posibilidad de cooptación de derecho para designar al presidente de los Estados Unidos de América, pues conforme a la disposición contenida en la sección 2 de la 25 enmienda constitucional, ratificada el 10 de febrero de 1967: "Siempre que esté vacante la Vicepresidencia, el presidente nombrará un vicepresidente, que asumirá el cargo cuando obtenga la confirmación correspondiente por voto mayoritario de ambas Cámaras del Congreso". Y como la sección 1 de la citada enmienda 25 dispone que: "En caso de que el presidente sea removido del cargo o de que se produzca su fallecimiento o dimisión, el vicepresidente se convertirá en presidente", y la sección 3 y 4 de la misma enmienda contienen preceptos similares para que el vicepresidente se convierta en presidente interino, podemos afirmar que éste es un caso de cooptación franca, por la que el presidente de Estados Unidos de América, designa a su sucesor, sin que medie elección ni participación del pueblo.

Gerald Ford fue el primero, y hasta ahora el único presidente de Estados Unidos de América, designado mediante cooptación, porque al renunciar el vicepresidente Spiro T. Agnew en 1973 a la Vicepresidencia, el presidente Richard M. Nixon lo nombró vicepresidente, y al renunciar Nixon a la Presidencia, Ford automáticamente se convirtió en presidente y nombró vicepresidente a Nelson A. Rockefeller, para que por primera vez en los anales estadounidenses ocupasen la Presidencia y Vicepresidencia de ese país, dos personas designadas por sus respectivos antecesores, en una típica cooptación de iure, sin ninguna intervención del pueblo.

3 Sani, Giacomo, "Cooptación”, en Bobbio, Norberto y Matteucci, Nicola, Diccionario de política, trad. de Jorge Tula y otros, México, Siglo XXI, 1981, t. a-j, p. 430. 
En el siglo XXI, la forma a la que se le atribuye mayor afinidad con la libertad e igualdad que reclaman la dignidad humana y la democracia, es la elección, la cual inicialmente se atribuyó al azar y, posteriormente, cuando se comprobó que éste no siempre era aliado de la sindéresis, se resolvió recurrir al voto mayoritario de los gobernados.

\section{El sigilo del voto}

Se conoce como sufragio o voto el instrumento que tiene todo ciudadano para ejercer su derecho a participar en el gobierno de su país, directamente (voto pasivo) o por medio de representantes libremente escogidos (voto activo); derecho previsto en el artículo 35 de la Constitución Política de los Estados Unidos Mexicanos, e incluido en diversos instrumentos internacionales como la Declaración Universal de Derechos Humanos de 1948 (artículo 21), en la Declaración Americana de los Derechos y Deberes del Hombre de 1948, en el Pacto Internacional de Derechos Civiles y Políticos de 1966 (artículo 25), y en la Convención Americana sobre Derechos Humanos de 1969 (artículo 23), instrumentos internacionales suscritos por el presidente de la República y aprobados por el Senado, que consagran el voto secreto.

Para que el voto se ajuste a los cánones de la democracia debe ser libre, es decir, emitirse en libertad, sin presión, coacción, violencia o intimidación que vicien la voluntad del elector, la cual puede violentarse mediante el empleo de fuerza física o amenazas que impliquen riesgo de perder la vida, la salud, la libertad, los bienes, el empleo o la honra.

La emisión del voto admite diversas modalidades, como la oral, la posicional, la escrita y la electrónica; las dos primeras son públicas, la escrita puede ser tanto pública como secreta, al igual que la electrónica.

En la modalidad oral, el elector da a conocer de viva voz el sentido de su voto, lo que excluye la posibilidad de que sea secreto; lo mismo ocurre con la posicional, conforme a la cual el elector, a mano alzada, o poniéndose de pie, expresa el sentido de su voto. Para explicar lo que al principio del siglo XX era el voto secreto, Guillermo Cabanellas señaló que era: "El que no permite reconocer al votante, por votar éste en papeleta doblada, introducida dentro de un sobre, por bolas 
blancas o negras o de otro modo que garantice la independencia del elector".

La emisión del voto mediante la forma escrita permite guardar en secreto el sentido del mismo, igual ocurre con la emisión electrónica, aun cuando ambas modalidades pueden utilizarse en un sistema electoral en el que el voto sea público.

\section{La Constitución de Cádiz}

La Constitución Española de 1812, con vigencia en la Nueva España, adoptó un sistema electoral indirecto de tercer grado, en cuya primera etapa, a desarrollarse en las juntas electorales de parroquia, se elegían compromisarios mediante voto oral (artículo 51); en la segunda etapa, que tenía lugar en las juntas electorales de partido se designaban electores mediante voto secreto escrito en una cédula (artículo 73), en tanto que en la tercera y última etapa, celebrada en las juntas electorales de provincia, se volvía al voto oral, y por tanto público, para elegir a los diputados a las Cortes (artículo 88).

\section{La Constitución de Apatzingán}

El Decreto Constitucional para la Libertad de la América Mexicana, mejor conocido como Constitución de Apatzingán, dispuso la forma pública de la emisión del voto, en sus modalidades oral y pública, al establecer para la designación de elector por mayoría de votos, dentro de un sistema de elección indirecta de tercer grado que incluía comicios en juntas electorales de parroquia, juntas electorales de partido y juntas electorales de provincia que finalmente nombraban a los diputados.

Para la elección en las juntas electorales de parroquia, según prevenía su artículo 71: "Cada votante se acercará a la mesa, y en voz clara e inteligible nombrará los tres individuos que juzgue más idóneos para electores. El secretario escribirá estos sufragios, y los manifestará al

4 Diccionario de derecho usual, 6a. ed., Buenos Aires, Bibliográfica Omeba, t. IV, p. 441 . 
votante, al presidente y a los escrutadores, de modo que todos queden satisfechos".

En las juntas electorales de partido, integradas con los electores nombrados en las juntas electorales de parroquia, una vez depurado el padrón de electores de parroquia, se procedía entre éstos a la elección de electores de partido, según lo dispuesto en el artículo 87 del citado ordenamiento: "Se procederá en seguida a la votación, haciéndola a puerta abierta por medio de cédulas en que cada elector exprese los tres individuos que juzgue más a propósito: recibirá las cédulas el secretario, las leerá en voz alta y manifestará al presidente”.

Procedimiento semejante al señalado en el párrafo anterior se seguía en las juntas electorales de provincia para la designación, por mayoría de votos, de un diputado por cada provincia, quedando electo el que hubiere obtenido la votación más alta, y como suplente el que le siguiere en número de votos logrados; en caso de empate se sorteaba el nombramiento.

\section{Las Bases para las elecciones del Congreso Constituyente de 1823}

Expedidas el 17 de junio de 1823, las Bases para las elecciones del nuevo Congreso previeron una sistema electoral de tercer grado, parecido al establecido en la Constitución de Apatzingán, compuesto de juntas primarias o municipales, juntas secundarias o de partido, y juntas de provincia, para designar electores primarios, electores secundarios, y diputados, respectivamente; el voto en las juntas primarias y en las de provincia era oral (artículos 31 y 63), en tanto que en las juntas secundarias o de partido, era escrito y secreto (artículo 59).

\section{La Constitución Federal de 1824}

Nada dispuso la Carta de 1824 acerca de la emisión del voto habida cuenta que en su artículo 9o. previno: "Las cualidades de los electores se prescribirán constitucionalmente por las legislaturas de los estados, a las que también corresponde reglamentar las elecciones conforme a los principios que se establecen en esta Constitución”. 


\section{Reglas para las Elecciones de Diputados y de Ayuntamientos del Distrito y Territorios de la República}

Emitidas estas reglas el 12 de julio de 1830, introdujeron el esquema de elección indirecta de segundo grado, en cuya primera etapa, correspondiente a las elecciones primarias, iniciaron la modalidad de emisión del voto a través de boletas electorales nominales individualizadas, pues se emitía cada una con el nombre de cada uno de los electores que figuraban en el padrón de vecinos de cada manzana o sección que tuviere derecho a votar, con lo que el sentido del voto quedaba registrado con precisión.

Las boletas eran del tamaño de un cuarto de pliego de papel, conforme al formato siguiente (artículo 13):

Elección de diputados al Congreso para los años de ............

Parroquia:

Manzana núm.: Sección núm.:

Ciudadano N. (el que recibe la boleta)

(Firma del comisionado)

En cambio, en la segunda etapa correspondiente a las elecciones secundarias, en las que se designaba a los diputados mediante voto secreto previsto en el artículo 54 del tenor siguiente: "A las nueve de la mañana del día señalado en la Constitución federal, se hará la elección de diputados propietarios y suplentes por escrutinio secreto, mediante cédulas que echará cada elector en un vaso puesto al efecto sobre la mesa, acercándose para ello cada uno por el orden de sus asientos".

\section{Convocatoria para la Elección del Congreso Constituyente de 1857}

Expedida esta Convocatoria el 17 de octubre de 1855, regresó al sistema de elección indirecta de tercer grado, cuyas tres etapas se desarrollaban a través de juntas primarias, juntas secundarias o de partido y juntas de estado, en las que las primeras nombraban electores primarios, las segundas, electores secundarios, y las últimas, diputados propietarios y suplentes, mediante boletas electorales nominales los primeros, y por voto secreto los electores secundarios y los diputados. 


\section{La Ley Orgánica Electoral de 1857}

Por su parte, la Ley Orgánica Electoral del 12 de febrero de 1857 dispuso un sistema de elección indirecta de segundo grado, con nombramiento de electores mediante boleta electoral nominal, y designación de diputados mediante voto secreto a través de cédulas. Bajo procedimiento similar se elegía al presidente de la República.

\section{Reformas a la Ley Electoral del 19 de diciembre de 1911}

El sistema de elección indirecta de diputados y senadores se mantuvo en nuestra normativa hasta que el 22 de mayo de 1912 el Congreso de la Unión decretó las reformas a la Ley Electoral del 19 de diciembre de 1911, en virtud de las cuales se dispuso la elección directa mediante voto secreto por cédula, sistema que luego se aplicó también a la elección presidencial y, con algunas variantes, se mantiene hasta la fecha.

\section{Justificación del secreto del voto}

La representación política da sustento a la democracia representativa, la cual se basa en el voto secreto. Winston Churchill manifestó al respecto: "En el fondo de todos los elogios tributados a la democracia, se haya el ciudadano corriente que penetra al cuarto aislado, lápiz en mano, y traza una cruz sobre una papeleta; no hay retórica ni razonamiento sofístico, capaces de restar importancia a esa actitud trascendental de la vida ciudadana”.

A efecto de que el voto se emita en libertad se requiere que sea secreto, porque de lo contrario el que lo emite queda expuesto a represalias de diversa índole. En épocas anteriores la emisión del voto en los comicios electorales era pública pues se votaba a mano alzada, lo cual se traducía en fuertes presiones para orientar el sufragio a favor de un candidato determinado, con lo que se inhibía la libertad del votante; con el avance de la democracia se consagró el voto libre y secreto. 
Cuando el voto no es secreto está en riesgo su libertad, porque, insisto, si no se mantiene cuidadosamente reservado y oculto el sentido del mismo, puede haber represalias de personas o grupos sociales, gremiales o políticos, o incluso, de las mismas autoridades; de ahí la tendencia de la normativa electoral contemporánea de mantener oculto el sentido del voto, es decir de proteger el secreto del sufragio. "El carácter secreto del voto coadyuva en forma importante para hacer menos vulnerable al sujeto del derecho electoral frente a presiones de tipo externo y garantiza una mayor participación en los comicios". ${ }^{5}$

José Woldenberg explica que el voto es secreto: "Con el fin de evitar probables y/o reales presiones sobre los electores. Es decir, garantizar que sólo el ciudadano conozca el sentido de voto tiene como fundamento crear un dique contra intentos diversos de presión o soborno de los electores". 6

Consiste la libertad del sufragio en que el voto se pueda emitir sin soborno, presión, intimidación o coacción alguna, e implica, además, que el voto no sea mercancía susceptible de venderse y de comprarse. Por ello, como observa Enrique Arnaldo Alcubilla, "es una premisa fundamental del sistema (electoral democrático) el que las elecciones no pueden ser libres si quienes gobiernan pueden manejarlas para afianzarse en el poder, porque las elecciones libres tienen como finalidad esencial la legitimación y la limitación del poder"?

Un tema que preocupa a la doctrina jurídica electoral es el relativo al secreto y a la venta del voto, respecto del cual el jurista argentino Eduardo A. Quian Solari apunta:

Un recurso utilizado desde la antigüedad para obtener la victoria electoral, es el de la compra del sufragio mediante el pago de una suma determinada de dinero. Este tipo de fraude es muy fácil de llevarse a cabo cuando el sufragio no es secreto, pues se puede constatar por quien vota el elector. ${ }^{8}$

5 Higuera Castro, Francisco, "El sufragio. Comentarios sobre su origen y evolución", Aequitas, Revista jurídica del Poder Judicial del Estado de Sinaloa, Segunda época, núm. 29, abril de 1997, núm. 115.

6 Woldenberg, José, El voto, México, Academia Mexicana de Derechos Humanos, 1997, p. 14.

Alcubilla, Enrique Arnaldo, El régimen electoral en España, Madrid, Centro de Estudios Políticos y Constitucionales, 1999, p. 113.

8 Quian Solari, Eduardo A., "Sufragio", Enciclopedia jurídica Omeba, Buenos Aires, Bibliográfica Omeba, t. XXV, 1968, p. 944. 
En efecto, si no se mantiene en secreto el sentido del voto se propicia la corrupción por la vía de la compraventa del sufragio, al exhibir el votante vendedor al representante del partido comprador, la boleta electoral antes de introducirla a la urna, para probar el cumplimiento de su delictuoso compromiso, por lo que ese secreto debe ser, a la par, un derecho y una obligación del sufragante, lo que significa que, por una parte, terceros no deben vulnerar ese carácter reservado, y por otra, el emisor del voto tampoco debe exhibirlo, porque eso permitiría al comprador del voto comprobar el cumplimiento del pacto indebido de votar en determinado sentido para cobrar un precio y, además, significaría un acto de proselitismo en fecha prohibida como es el día de la elección.

En Roma, en tiempos de Pompeyo y César, el voto electoral ya estaba en el mercado, pues al decir de Montesquieu, Cneo Pompeyo (106-48 a.C.) $)^{9}$ "corrompió al pueblo a fuerza de dinero y puso precio en las elecciones al voto de cada ciudadano", y en este contexto de corrupción política electoral, Julio César, al confrontarse con Pompeyo "empleó contra él las fuerzas que él mismo le había dado y sus mismo artificios; perturbó la ciudad con sus emisarios y se hizo dueño de las elecciones, cónsules, pretores, tribunos, fueron comprados al precio que ellos mismos señalaron". ${ }^{10}$

En el siglo XVIII, en plena época del terror de la Revolución francesa, con la guillotina funcionando a su máxima capacidad, Maximilien Robespierre se pronunció porque el voto fuera público a efecto de que fuera la salvaguarda del pueblo, y, por conducto del Consejo General de la Comuna de París, dispuso que la emisión del voto fuera en público y en voz alta, con lo que logró que los electores votaran en el sentido que él deseaba.

Al final del siglo XIX y principios del XX se discutió con intensidad si el voto debía ser público o privado: John Stuart Mill sostuvo que por ser el voto una función debería ser público. ${ }^{11}$ En cambio, Joseph Barthelemy y Paul Duez estimaron que no se trataba de una función sino

9 Montesquieu, Grandeza y decadencia de los romanos, México, Secretaría de Educación Pública, 1947, pp.36 y 37.

10 Ibidem, p. 37.

11 Stuart Mill, John, El gobierno representativo, trad. de Siro García del Mazo, Madrid, Librería de Victoriano Suárez, 1878, pp. 487 y 488. 
de un derecho cuyo ejercicio debería ser protegido en su privacidad, para ponerlo al abrigo de la intimidación y abatir la corrupción. ${ }^{12}$

No debe olvidarse que la garantía de autenticidad de una elección radica, en buena medida en que el voto sea libre, y para ello es indispensable que sea secreto, por lo que hoy por hoy coinciden, en principio, la doctrina, la legislación y la jurisprudencia, en respetar y proteger el secreto del voto, ${ }^{13}$ incluso se ha acuñado el neologismo secrecía - por cierto no reconocido por la Real Academia Española de la Lengua-, que hace referencia al carácter reservado del sufragio, mas no se ha precisado su esencia, su temporalidad, ni tampoco su ámbito espacial, circunstancia que puede dar lugar, en la práctica, a vulnerar el secreto del voto y los bienes jurídicos que éste trata de tutelar, mediante diversos mecanismos, entre los cuales destaca la encuesta electoral.

Consecuentemente, es necesario precisar la esencia del secreto del voto, que en mi opinión es una faceta de la libertad de pensamiento, consistente en mantener absolutamente independiente al yo interno para poder pensar sin presiones ni cortapisas, y estar cada quien en condiciones de adoptar los principios morales que considere válidos para sustentar sus ideas y su actuación, tanto en el ámbito filosófico, como en el religioso, el económico y, desde luego, el político.

Estimo que el secreto del voto es, también, una modalidad de la libertad política, en cuya virtud el individuo hace uso del dominio de su pensamiento y de su voluntad, vamos, de su libre albedrío, para determinar el sentido o el beneficiario de su voto activo.

El momento decisivo de la emisión del voto es cuando el elector marca en la boleta electoral por cuál candidato y/o partido vota, de ahí la importancia de preservar el carácter secreto del voto, porque como dice Luis A. Gálvez Muñoz:

12 Barthelemy Joseph y Duverger, Maurice, Instituciones politicas y derecho constitucional, trad. de Isidro Molas y otros, 5a. ed., Barcelona, Ariel, 1970, p. 28.

13 La Sala Superior del Tribunal Electoral del Poder Judicial de la Federación ha sostenido que el voto activo, "debe ser ejercido bajo los principios del sufragio universal, libre, secreto y directo, que implica, entre otros aspectos, la posibilidad de votar ausente de manipulación, presión, inducción o coacción alguna”. Gaceta de Jurisprudencia y Tesis en materia electoral, Tribunal Electoral del Poder Judicial de la Federación, año 2, núm. 4, 2009, pp. 34 y 35. 
No hay dudas por nuestra parte a la hora de señalar al acto de votación y, más en concreto, al momento de confección del voto, de introducción de la papeleta en el sobre de votación, como el auténtico momento decisivo de las elecciones. En él toma forma el sentido y valor de la democracia. ${ }^{14}$

En este orden de ideas, falta precisar la naturaleza, alcance, límites, temporalidad y ámbito espacial de la privacidad política que entraña el secreto del voto; es decir, aclarar si mantener en reserva el sentido del voto es un derecho o una obligación; ¿cuál es su ámbito temporal?, ¿se reduce simplemente al momento en que se marca en la boleta electoral el beneficiario del voto?, o ¿se protege también el futuro y el pasado del voto?, es decir, la intención y la historia del mismo.

Por tanto, ¿puede cualquier fisgón o entrometido, amateur o profesional, tratar impunemente de romper mi privacidad política para escudriñar la intención de mi voto o a favor de quién lo emití?

El artículo 117 de la Ley de Instituciones de Crédito resguarda celosamente el secreto bancario que tanto favorece el lavado de dinero y la corrupción $-\mathrm{y}$ por cierto, no está contemplado en la Declaración Universal de Derechos Humanos, ni en la Convención Americana de Derechos Humanos, ni tampoco en el Pacto Internacional de Derechos Civiles y Políticos-, en afán de proteger el derecho a la privacidad de sus clientes y usuarios, a cuyo efecto establece un rígido sistema de reserva de esa información para que sólo se proporcione a ciertas autoridades, mediante un complicado procedimiento, ya que dispone:

Artículo 117.- La información y documentación relativa a las operaciones y servicios a que se refiere el artículo 46 de la presente Ley, tendrá carácter confidencial, por lo que las instituciones de crédito, en protección del derecho a la privacidad de sus clientes y usuarios que en este artículo se establece, en ningún caso podrán dar noticias o información de los depósitos, operaciones o servicios, incluyendo los previstos en la fracción XV del citado artículo 46, sino al depositante, deudor, titular, beneficiario, fideicomitente, fideicomisario, comitente o mandante, a sus representantes legales o a quienes tengan otorgado poder para disponer de la cuenta o para intervenir en la operación o servicio.

Como excepción a lo dispuesto por el párrafo anterior, las instituciones de crédito estarán obligadas a dar las noticias o información a que se

14 Gálvez Muñoz, Luis A., La confección del voto, Madrid, Centro de Estudios Políticos y Constitucionales, 2009, p. 20. 
refiere dicho párrafo, cuando lo solicite la autoridad judicial en virtud de providencia dictada en juicio en el que el titular o, en su caso, el fideicomitente, fideicomisario, fiduciario, comitente, comisionista, mandante o mandatario sea parte o acusado. Para los efectos del presente párrafo, la autoridad judicial podrá formular su solicitud directamente a la institución de crédito, o a través de la Comisión Nacional Bancaria y de Valores.

Las instituciones de crédito también estarán exceptuadas de la prohibición prevista en el primer párrafo de este artículo y, por tanto, obligadas a dar las noticias o información mencionadas, en los casos en que sean solicitadas por las siguientes autoridades:

I. El Procurador General de la República o el servidor público en quien delegue facultades para requerir información, para la comprobación del cuerpo del delito y de la probable responsabilidad del indiciado;

II. Los procuradores generales de justicia de los Estados de la Federación y del Distrito Federal o subprocuradores, para la comprobación del cuerpo del delito y de la probable responsabilidad del indiciado;

III. El Procurador General de Justicia Militar, para la comprobación del cuerpo del delito y de la probable responsabilidad del indiciado;

IV. Las autoridades hacendarias federales, para fines fiscales;

V. La Secretaría de Hacienda y Crédito Público, para efectos de lo dispuesto por el artículo 115 de la presente Ley;

VI. El Tesorero de la Federación, cuando el acto de vigilancia lo amerite, para solicitar los estados de cuenta y cualquier otra información relativa a las cuentas personales de los servidores públicos, auxiliares y, en su caso, particulares relacionados con la investigación de que se trate;

VII. La Auditoría Superior de la Federación, en ejercicio de sus facultades de revisión y fiscalización de la Cuenta Pública Federal y respecto a cuentas o contratos a través de los cuáles se administren o ejerzan recursos públicos federales;

VIII. El titular y los subsecretarios de la Secretaría de la Función Pública, en ejercicio de sus facultades de investigación o auditoría para verificar la evolución del patrimonio de los servidores públicos federales.

La solicitud de información y documentación a que se refiere el párrafo anterior, deberá formularse en todo caso, dentro del procedimiento de verificación a que se refieren los artículos 41 y 42 de la Ley Federal de Responsabilidades Administrativas de los Servidores Públicos, y

IX. La Unidad de Fiscalización de los Recursos de los Partidos Políticos, órgano técnico del Consejo General del Instituto Federal Electoral, para el ejercicio de sus atribuciones legales, en los términos establecidos 


\begin{abstract}
en el Código Federal de Instituciones y Procedimientos Electorales. Las autoridades electorales de las entidades federativas solicitarán y obtendrán la información que resulte necesaria también para el ejercicio de sus atribuciones legales a través de la unidad primeramente mencionada.
\end{abstract}

De conformidad con esa legislación mercantil, ningún particular, persona física o moral, curiosa o investigadora profesional de mercados, puede obtener lícitamente información acerca del importe abonado el día de hoy a mi cuenta bancaria en la que la Universidad Nacional Autónoma de México me deposita periódicamente mis remuneraciones salariales, ni de lo depositado en ella el año pasado, ni siquiera la fecha en que se espera se haga el siguiente depósito en ella, pues está protegido el secreto presente, pasado y futuro de mi cuenta bancaria.

En tanto que nuestra normativa electoral olvida el carácter secreto del voto consagrado en instrumentos internacionales celebrados por el presidente de la República con aprobación del Senado, mismos que, junto con la Constitución y las leyes del Congreso de la Unión emanadas de ella, son la ley suprema de México, y permite a las encuestadoras transgredirlo impunemente.

El artículo 851 del Código Civil Federal nos protege contra fisgones en la privacidad del hogar, al prohibir tener ventanas, para asomarse, ni balcones $\mathrm{u}$ otros voladizos semejantes, sobre la propiedad del vecino, en cambio el Código Federal de Procedimientos e Instituciones Electorales no nos protege contra los fisgones que pretenden vulnerar el secreto de nuestro voto en gestación o el de nuestro voto emitido.

A nadie escapa que quien conozca la intención del voto de otra persona puede tratar de presionarlo para que cambie el sentido de su voto, y quien conozca a favor de quién lo emitió puede, además, llegar a ejercer represalias.

En razón de la trascendencia de la elección de los funcionarios públicos, el elector debe disponer de cierto periodo de tiempo para la determinación del candidato en cuyo favor emitirá su voto; se trata, entonces, del periodo durante el cual el voto se encuentra en gestación: la pregunta es: ¿el secreto del voto sólo protege su emisión, o también incluye su gestación?, ¿ sólo cubre el momento en que se cruza la boleta respectiva y el elector permanece en el recinto de la casilla?, ¿debe reducirse al momento de la emisión y a unos cuantos días previos a la misma? 


\section{La encuesta electoral}

Se puede explicar la encuesta electoral como el acopio de datos obtenidos mediante consulta o interrogatorio, referentes a estados de opinión, costumbres, nivel económico o cualquier otro aspecto de la actividad humana, la encuesta puede versar sobre preferencias electorales; con ese propósito la utilizó en Estados Unidos un periódico local de Harrisburg, Pennsylvanian, en 1824.

La señora Alex Miller, durante la primera presidencia de Franklin Delano Rooselvet, pretendió ocupar un cargo electoral; el desarrollo de su campaña fue orientado por las encuestas de preferencia electoral realizadas por su yerno George Gallup, quien de esta manera se inició en esa actividad, para luego escribir su tesis doctoral sobre ese tema, y después fundar una de las empresas más exitosas del mundo en el desarrollo de encuestas de diversos tópicos, principalmente preferencias electorales.

La evaluación de la calidad de un cargamento de naranjas examinando sólo las que están en la parte superior del contenedor, conducirá a una conclusión errónea, si deliberadamente las de encima, todas de buena calidad, ocultan al resto que no lo son; para una correcta evaluación se requiere integrar la muestra a examinar, con naranjas de todas las capas y de distintos puntos del contenedor. Igual ocurre en la encuesta social, un mal diseño de la muestra conduce a resultados erróneos.

Las encuestas se realizan, hoy en día, sobre las más diversas cuestiones: desempleo, radiodifusora escuchada o canal de televisión sintonizado, aborto, pena de muerte, y preferencia electoral, entre otros, ello ha propiciado el desarrollo de una técnica de investigación social basada en la teoría matemática conocida como muestreo probabilístico, que conduce al conocimiento de opiniones, preferencias o actitudes de una colectividad, mediante la respuesta a un cuestionario presentado a un pequeño número de sus miembros que constituya una muestra representativa del todo. Desarrollada la encuesta social con estricto apego a las reglas científicas del muestreo probabilístico, sus resultados serán tan exactos que su posibilidad de error es muy reducida.

En la práctica, los resultados de las encuestas suelen alterarse con fines aviesos, por ejemplo, en el caso de las encuestas electorales, se 
falsean sus resultados con el propósito de influir, mediante su publicación o divulgación, en el ánimo de un sector amplio del electorado, bajo el supuesto de que, cuando menos, un amplio sector de la masa electoral carece de intención propia de voto, y desean sumar su voto al de la mayoría a efecto de sentirse triunfadores; en esa masa electoral la intención individual de voto se desvanece para dar paso a una intención colectiva, la de la masa electoral, cuyos miembros se sumarán a la que creen que es la intención de la mayoría. De esta suerte, la encuesta electoral falseada se convierte en instrumento de publicidad electoral engañosa, con el propósito de producir un efecto de movimiento ondulatorio que, a semejanza de la piedra que cae en el agua de una alberca, se genere en la intención colectiva del voto.

Empero, al margen de la exactitud, acierto y autenticidad de las encuestas de preferencia electoral, y de las encuestas de salida o a boca de urna, debe elucidarse si éstas atentan o no contra el carácter secreto que debe caracterizar al voto.

Así como no se legitima el fraude electoral por el hecho de ser una añeja e inveterada costumbre en muchos países, tampoco se legitima per se, la ya centenaria y extendida práctica de encuestas electorales.

En principio, parece justo prohibir las encuestas electorales nominales, lo mismo que las realizadas por los patrones en los centros de trabajo, o las efectuadas en escuelas de adultos, organizaciones sindicales y agrarias, así como las telefónicas, las domiciliarias o las practicadas a conductores de vehículos, por el grave riesgo de represalias potenciales que representan para los encuestados, en razón de su fácil identificación.

Toda vez que la encuesta de salida o exit poll - que entrevista a los electores al salir de las casillas para conocer a favor de quién votaron - realizada por instituciones particulares, tiene por finalidad determinar quién fue el ganador de una elección, su legitimidad es altamente cuestionable, no sólo porque atenta contra el secreto del voto, sino, también, por tratarse de una actividad que es parte de la función pública electoral, la cual es indelegable, por lo que, en mi opinión, debieran prohibirse, pues tratan de realizar, por cierto con menores elementos de juicio, un cómputo virtual sobre el mismo tema del cómputo real, que es una etapa del ejercicio de la indelegable función pública electoral.

La realización de encuestas de preferencia electoral, se regula en el orden jurídico federal mexicano mediante diversos ordenamientos normativos, entre los cuales destacan los siguientes: 


\section{- Constitución Política de los Estados Unidos Mexicanos}

Artículo 41. (fracción V, párrafo décimo)

El Instituto Federal Electoral tendrá a su cargo en forma integral y directa, además de las que le determine la ley, las actividades relativas a... la regulación de la observación electoral y de las encuestas o sondeos de opinión con fines electorales...

\section{- Código Federal de Instituciones y Procedimientos Electorales}

\section{Artículo 237}

5. Quien solicite u ordene la publicación de cualquier encuesta o sondeo de opinión sobre asuntos electorales, que se realice desde el inicio del proceso electoral hasta el cierre oficial de las casillas el día de la elección, deberá entregar copia del estudio completo al Secretario Ejecutivo del Instituto, si la encuesta o sondeo se difunde por cualquier medio. En todo caso, la difusión de los resultados de cualquier encuesta o sondeo de opinión estará sujeta a lo dispuesto en el párrafo siguiente.

6. Durante los tres días previos a la elección y hasta la hora del cierre oficial de las casillas que se encuentren en las zonas de husos horarios más occidentales del territorio nacional, queda prohibido publicar o difundir por cualquier medio, los resultados de encuestas o sondeos de opinión que tengan por objeto dar a conocer las preferencias electorales de los ciudadanos, quedando sujetos quienes lo hicieren, a las penas aplicables a aquellos que incurran en alguno de los tipos previstos y sancionados en el artículo 403 del Código Penal Federal.

7. Las personas físicas o morales que pretendan llevar a cabo encuestas por muestreo para dar a conocer las preferencias electorales de los ciudadanos o las tendencias de las votaciones, adoptarán los criterios generales de carácter científico, que para tal efecto emita el Consejo General, previa consulta con los profesionales del ramo o las organizaciones en que se agrupen.

\section{- Código Penal Federal}

Artículo 403. Se impondrán de diez a cien días multa y prisión de seis meses a tres años, a quien: 
XIII. Durante los ocho días previos a la elección y hasta la hora oficial del cierre de las casillas que se encuentren en las zonas de husos horarios más occidentales del territorio nacional publique o difunda por cualquier medio los resultados de las encuestas o sondeos de opinión que den a conocer las preferencias de los ciudadanos.

- Normativa complementaria expedida por el Instituto Federal Electoral

Con fundamento en el artículo 41 constitucional y en el párrafo 7 del artículo 237 del Cofipe, el IFE, mediante Acuerdo de su Consejo General, determinó los criterios generales que deben adoptar las personas físicas o morales que pretendan llevar a cabo encuestas por muestreo para dar a conocer las preferencias electorales de los ciudadanos o las tendencias de las votaciones, los cuales fueron publicados en el Diario Oficial de la Federación del 18 de febrero de 2009, y distan mucho de proteger a cabalidad el secreto del voto, lo cual redunda en perjuicio de los electores, en aras de un discutible derecho de encuesta supuestamente derivado de las libertades de trabajo y de expresión.

Se incluyen en los Considerandos del Acuerdo del Consejo General por el que se establecen los lineamientos así como los criterios de carácter científico que deberán observar las personas físicas y morales que pretendan ordenar, realizar y/o publicar encuestas por muestreos, encuestas de salida y/o conteos rápidos durante el proceso electoral 2008-2009, los siguientes:

11. Por lo tanto, la divulgación detallada de las características metodológicas de las encuestas y sondeos sobre asuntos electorales es condición indispensable para que estos estudios efectivamente contribuyan al desarrollo democrático a través de la creación de una opinión pública mejor informada.

12. Que durante los procesos electorales anteriores, se realizaron y publicaron una gran cantidad de encuestas, sondeos, encuestas de salida y sondeos rápidos que contribuyeron a fortalecer la información de los electores para emitir su voto. Que la realización de encuestas electorales debe realizarse en un ámbito de libertad metodológica y científica, sin límites al ejercicio profesional de la democracia.

13. Que de una interpretación sistemática del artículo 41, párrafo noveno, base V, de la Constitución Política de los Estados Unidos Mexica- 
nos, así como del numeral 237 del Código Federal de Instituciones Políticas y Procesos Electorales, se desprende que una de las funciones del Instituto Federal Electoral es vigilar y garantizar el debido desarrollo de la jornada electoral. En consecuencia, conviene establecer lineamientos mínimos relativos a las encuestas de salida y/o estudios de conteo rápido con fines electorales, que se realicen durante la citada jornada electoral para facilitar su realización sin que impacten el buen desarrollo de la jornada electoral.

Como puede advertirse fácilmente, la secrecía del voto consagrada en los instrumentos internacionales y en la legislación electoral mexicana no es tema de la normativa relativa a las encuestas electorales, desdén que se agrava porque en los considerandos del Acuerdo del Consejo General del Instituto Federal Electoral que acabo de transcribir, claramente se admite que la difusión de tales encuestas y sondeos que vulneran el secreto del voto en las diversas etapas de su gestación ejercicio, influyen en el ánimo del elector, toda vez que "contribuyeron a fortalecer la información de los electores para emitir su voto" (Considerando 12).

Además, la normativa en comento no evita la deformación deliberada de los resultados de las encuestas, para inducir el sentido del voto, habida cuenta que su difusión es indiscutiblemente un instrumento de propaganda electoral

Situación parecida, en materia electoral, se observa en la normativa local, como ocurre en el Distrito Federal, cuyo Código de Instituciones y Procesos Electorales, previene:

Artículo 326. Las encuestas de opinión que se realicen desde el inicio de las campañas hasta el cierre oficial de las casillas el día de la elección y la difusión de los resultados de las mismas, estarán sujetos a los acuerdos del Consejo General y a lo dispuesto en este Código.

Quien ordene la publicación o difusión de cualquier encuesta o sondeo de opinión sobre las campañas electorales, deberá entregar dentro de los tres días siguientes un ejemplar del estudio completo al Consejero Presidente del Consejo General, en el que incluirá la metodología, el nombre de la empresa que lo realiza y, en su caso, el nombre del patrocinador de la encuesta.

En todos los casos la metodología utilizada en las encuestas o sondeos de opinión estará a disposición de los Partidos Políticos y Coaliciones en la Secretaría Ejecutiva del Instituto Electoral. 
Durante los ocho días previos a la elección y hasta la hora del cierre oficial de las casillas, queda prohibido publicar o difundir por cualquier medio, los resultados de encuestas o sondeos de opinión que tengan por objeto dar a conocer las preferencias electorales de los ciudadanos, quedando sujetos quienes lo hicieren, a las penas y sanciones correspondientes.

Las personas físicas o morales que pretendan llevar a cabo encuestas por muestreo o de cualquier otro tipo para conocer las preferencias electorales de los ciudadanos o las tendencias de las votaciones el día de las elecciones, deberán informar al Consejo General con una antelación de por lo menos treinta días.

Más parca, la Ley Electoral del Estado de Nuevo León se concreta a prevenir al respecto:

Artículo 139. Quien solicite u ordene la publicación de cualquier encuesta o sondeo de opinión sobre asuntos electorales que se realice desde el inicio de las campañas hasta el cierre oficial de las casillas el día de la elección, deberá entregar copia del estudio completo al Presidente de la Comisión Estatal Electoral, si la encuesta o sondeo se difundirá por cualquier medio. En todo caso, la difusión de los resultados de cualquier encuesta o sondeo de opinión estará sujeta a lo dispuesto en el párrafo siguiente.

Si no se da cumplimiento a lo dispuesto en el párrafo anterior, la Comisión Estatal Electoral de oficio deberá, en igualdad de circunstancias, establecer públicamente que la difusión no fue hecha del conocimiento de ese organismo. Lo anterior, con cargo al candidato y subsidiariamente al partido político, lo que se contabilizará dentro del tope de campaña.

Durante los ocho días previos a la elección y hasta la hora del cierre oficial de las casillas queda prohibido publicar o difundir, por cualquier medio, los resultados de encuestas o sondeos de opinión que tengan por objeto dar a conocer las preferencias electorales de los ciudadanos.

Artículo 297. La Comisión Estatal Electoral impondrá multa de cuatrocientos a ochocientos días de salario mínimo general vigente para la ciudad de Monterrey, a la persona que:

VII. Durante los ocho días naturales previos a la elección y hasta la hora oficial del cierre de las casillas, publique o difunda por cualquier medio los resultados de encuestas o sondeos de opinión que den a conocer las preferencias electorales de los ciudadanos, sobre los candidatos, coaliciones o partidos políticos contendientes en las elecciones locales; 
No omito señalar que la doctrina jurídica electoral, a través de prestigiados juristas, considera útiles las encuestas electorales y recomienda su difusión para una mejor información del electorado. ${ }^{15}$

La idea de que la publicación de las encuestas electorales contribuye a mantener mejor informados a los electores propicia la irracionalidad del voto y fomenta la emisión del sufragio del votante a favor del partido o candidato que supuesta o realmente encabeza las encuestas, lo cual promueve el sentido de masa del electorado para convertirlo en un conjunto inerte, dúctil y maleable, cuyo voto no se orientará por el análisis crítico de los candidatos, de los partidos y de sus propuestas y antecedentes, sino por las encuestas, porque para sentirse ganador sumará su voto al candidato que las encabece.

Cabe hacer notar que las encuestas no sólo orientan al votante ordinario integrante de la masa electoral sino también al dirigente que encabeza una organización sindical, empresarial, social o política que presume contar con el capital electoral que representa el caudal de votos de sus agremiados, seguro de que habrán de emitirse por quien él indique, así, el resultado de las encuestas le orillan a la cargada.

En la política mexicana, la tendencia a apoyar incondicionalmente al candidato ganador o al que se percibe como el posible triunfador en una elección se le denomina la cargada. Es esta una combinación de pragmatismo y oportunismo puro que busca ofrecer al aspirante con ventaja, una fuerza adicional para garantizar el triunfo. ${ }^{16}$

En suma, la publicación de las encuestas electorales orienta tanto al votante aislado como al votante corporativo, aunque este último, como observa Shabot Asquenazi:

En ocasiones la llamada cargada termina siendo el fin de la carrera de uno u otro político, tanto porque su apuesta fracasa finalmente y su candidato pierde la elección, como por el hecho de ser considerado como un personaje sin convicciones propias, únicamente interesado en los beneficios políticos y económicos del ejercicio del poder y, por lo tanto, carente del

15 Corzo, Edgar, Cuestiones constitucionales, núm. 16, enero-junio de 2007.

16 Shabot Asquenazi, Ezra, "La cargada”, El Universal, 28 de mayo de 2012, primera sección, p. 14. 
más mínimo sentido de lealtad, que en política vale más que la propia eficiencia. ${ }^{17}$

En México, en la última elección presidencial, numerosas empresas encuestadoras hicieron el ridículo porque sus pronósticos guardaron una brecha enorme con los resultados electorales, lo que hace suponer una gran ineptitud, o, lo que es más probable, la alteración de los resultados obtenidos a efecto de proceder a su publicación durante la campaña electoral como instrumento de propaganda engañosa.

El evidente falseamiento de los resultados de las encuestas electorales ha provocado la exigencia académica y ciudadana de revisar y corregir la regulación de las mismas, mas no de suprimir esa actividad que atenta contra el secreto del voto consagrado en la Constitución y en diversos instrumentos internacionales.

\section{Recapitulación}

Diversos instrumentos internacionales, que junto con la Constitución y las leyes que de ella emanan integran la ley suprema de todos y cada uno de los países que los suscribieron, disponen el carácter secreto del voto electoral.

El propósito de guardar en secreto el sentido del voto es doble, porque por una parte trata de proteger al elector contra posibles presiones, amenazas y represalias a efecto de que pueda determinar libremente el sentido de su voto y, por otra parte, tiende a evitar su comercialización, pues suprime la comprobación de haber votado en el sentido pactado en su compraventa, por lo que, consecuentemente debe permanecer oculto no sólo durante el instante en que se deposita en la urna, sino extenderse al periodo de gestación de su sentido y al posterior de su emisión.

Una práctica generalizada que atenta contra el carácter reservado del voto es la de realizar encuestas electorales que tratan de conocer por quién intenta votar, o a favor de quién votó el elector.

17 Idem. 


\section{Conclusiones}

1. Así como se mantiene en secreto el monto del saldo de mi cuenta bancaria al día de hoy y a cualquier fecha anterior, y se guarda reserva acerca de la fecha en que espera el depósito en ella de mi sueldo correspondiente a la quincena en curso, es decir, el secreto bancario cubre el pasado, presente y futuro de mi cuenta bancaria, de igual modo, el secreto del voto debe resguardar el futuro, el presente y el pasado del proceso de emisión del voto, mediante la prohibición tanto de esculcar la intención del voto, como la exhibición de la boleta electoral -instantes antes de introducirla a la urna- que muestra por quién voto, como también la revelación, al salir de la casilla o en cualquier otro momento posterior, de por quién voté.

2. Consecuentemente, las encuestadoras deberían circunscribir su actividad a la investigación de preferencias en diversas materias, mas no respecto de la intención o el sentido del voto, porque con ello se viola el secreto del mismo consagrado en el derecho comparado, se pone en riesgo la libertad de su emisión y la seguridad de los electores.

3. Además, se debiera prohibir la exhibición de la boleta electoral en la casilla electoral respectiva para mostrar a los allí presentes -incluido el representante del candidato o partido comprador del voto- los términos en que se deposita la boleta en la urna correspondiente, y así poder cobrar el precio del voto. Mediante esta prohibición se eliminaría una de las formas de probar fehacientemente que el voto se emitió en determinado sentido.

4. De establecerse en la normativa electoral mexicana los referidos preceptos prohibitivos en consonancia con los preceptos de los instrumentos internacionales que disponen el carácter secreto del voto, no podría alegarse a favor de su inobservancia que se trata de una práctica universal y secular, toda vez que, como establece el principio jurídico reconocido en numerosos ordenamientos legales conforme al cual "Contra la observancia de la ley no puede alegarse desuso, costumbre o práctica en contrario”. 


\section{Bibliografía}

Alcubilla, Enrique Arnaldo, El régimen electoral en España, Madrid, Centro de Estudios Políticos y Constitucionales, 1999.

Barthelemy, Joseph et Duez, Paul, Traité elémentaire de droit constitutionnel, Paris, Dalloz, 1926,

Cabanellas, Guillermo, Diccionario de derecho usual, 6a. ed., Buenos Aires, Bibliográfica Omeba, 1968.

Corzo, Edgar, Cuestiones constitucionales, núm. 16, enero-junio de 2007.

Duverger, Maurice, Instituciones políticas y derecho constitucional, trad. Isidro Molas y otros, 5a ed. Barcelona, Ariel, 1970.

Gaceta de Jurisprudencia y Tesis en materia electoral, TEPJF, año 2, núm. 4, 2009.

Gálvez Muñoz, Luis A., La confección del voto, Madrid, Centro de Estudios Políticos y Constitucionales, 2009.

Higuera Castro, Francisco, "El sufragio. Comentarios sobre su origen y evolución”, Aequitas, Revista jurídica del Poder Judicial del Estado de Sinaloa, Segunda época, núm. 29, abril de 1997.

Montesquieu, El espíritu de las Leyes, trad. de Mercedes Blázquez y Pedro de Vega, Barcelona, Tecnos, 1984.

- - - Grandeza y decadencia de los romanos, México, Secretaría de Educación Pública, 1947.

Quian SolAri, Eduardo A., "Sufragio", Enciclopedia Jurídica Omeba, Buenos Aires, Bibliográfica Omeba, t. XXV, 1968.

SAni, Giacomo, "Cooptación", en Bobbio, Norberto y Matteucci, Nicola, Diccionario de política, trad. de Jorge Tula y otros, México, Siglo XXI, 1981.

Sнавот Asquenazi, Ezra, "La cargada", El Universal, 28 de mayo de 2012.

Stuart Mill, John, El gobierno representativo, trad. de Siro García del Mazo, Madrid, Librería de Victoriano Suárez, 1878.

Woldenberg, José, El voto, México, Academia Mexicana de Derechos Humanos, 1997. 